\title{
Research on Yantai Urban Image Shaping in the Background of China-South Korea Free Trade Area Construction
}

\author{
Yang Wang \\ Yantai Nanshan University \\ Longkou, Shandong, China 265713
}

\author{
Pingqing Zhang \\ Yantai Nanshan University \\ Longkou, Shandong, China 265713
}

\begin{abstract}
China-South Korea Free Trade Area negotiations have been officially completed and have entered substantial stage of operation. The construction of ChinaSouth Korea Free Trade Area will powerfully promote the pragmatic cooperation between the two countries and cultural and educational exchanges to achieve more fruitful results. In particular, Yantai is an important trading city of China-South Korea Free Trade Area. China-South Korea Free Trade Area will play a positive role in promoting the upgrade industries, foreign trade, urban construction and city tour of Yantai. Under the background of China-South Korea Free Trade Area construction, doing research on the shaping and promotion of Yantai city image will help to improve the tourism image of Yantai city, boost the communication and cooperation between Yantai and cities in South Korea and promote the important role and status of Yantai in China-South Korea Free Trade Area construction, which have an important realistic significance.
\end{abstract}

Keywords-China-South Korea Free Trade Area; city image shaping; Yantai

\section{RESEARCH BACKGROUND}

China-South Korea Free Trade Agreement Negotiation starts from May 2012. On February 25, 2015, China and South Korea finish all the initialed texts of China-South Korea Free Trade Agreement. On June 1, 2015, China and South Korea officially sign China-South Korea Free Trade Agreement, which signifies the formal completion of ChinaSouth Korea. The construction of China-South Korea Free Trade Area will make China and South Korea become good neighbors and good companies and walk shoulder to shoulder. The exchanges of politics, economy and culture of both sides will have a profound influence on system elements of city image such as urban management idea, urban behavior culture and urban landscape environment, etc. As an important city of Shandong Peninsula that has trade relations with South Korea, it's necessary for Yantai city to think about how to successfully shape and promote good city image under the background of China-South Korea Free Trade Area, which will have a good boosting effect on the position and influence of Yantai in economic, political and cultural fields of China-South Korea Free Trade Area construction. Besides, it will lay a solid foundation for the far-reaching urban future development of Yantai. Under the background of China-South Korea Free Trade Area construction, strengthening the shaping and promotion of Yantai city image will help to boost the exchanges and cooperation between Yantai and cities in South Korea and promote the important role and status of Yantai in ChinaSouth Korea Free Trade Area construction.

"Image" refers to specific shape or posture that can cause the thoughts and emotional activities of people. City image is the intuitive reflect of inner quality and cultural connotation of the city on external form of the city and also the deep impression that makes this city different from other cities. For internal effect, good city image can strengthen the cohesive force and centripetal force of the city, and raise the sense of belonging, sense of pride and the sense of mission of citizens for the city and make residents at all walks of life in the city focus on the development of the city; for external effect, good city image can improve social awareness of the city and help to improve competitive strength of the city.

\section{ConNotation OF City IMAgE SHAPING}

\section{A. City Image}

"Image" refers to specific shape or posture that can cause the thoughts and emotional activities of people. City image is the intuitive reflect of inner quality and cultural connotation of the city on external form of the city and also the deep impression that makes this city different from other cities. For internal effect, good city image can strengthen the cohesive force and centripetal force of the city, and raise the sense of belonging, sense of pride and the sense of mission of citizens for the city and make residents at all walks of life in the city focus on the development of the city; for external effect, good city image can improve social awareness of the city and help to improve competitive strength of the city.

\section{B. City Image Shaping}

City image shaping mainly refers to the planning layout and design of various elements in urban organizational structure and their interrelationships. The basic principles of city image shaping include: firstly, combine with local national culture and regional culture to shape city image which has its own characteristics; secondly, adhere to the 
people-centered principle; thirdly, must respect and carry forward characteristics that already have established by usage after a period of development; fourthly, city image shaping should obey the natural laws and show respect for nature during the nature remaking at the same time.

\section{Strategies of City Image Shaping on the Basis of Cultural Perspective}

Urban culture is a complicated and multi-level unity and the sum total of material wealth and spiritual wealth created by human in the process of urban development. Urban culture is contained in "hardware" such as architectural scene, street beautification, square planning and design, sculpture decoration, communal facilities and environmental health of the city; and "software" such as all production and life style of urban citizens and customs of the city. The two aspects of "software" and "hardware" have a silent transforming influence on each other and form different urban cultural style.

1) Urban culture is the spirit and pillar of city image and it is also the source of power that can make city image prosperous for long years. The shaping of city image is a systematical engineering and involves all aspects of the city. City image shaping should make efforts to seek a breakthrough. Urban culture is sedimentary deposits of urban historical development. The stability and uniqueness of culture decide that urban culture is the starting point of city image shaping. Urban culture supports city image through being internalized in the government and enterprises of the city and the behaviors and thoughts of the public. City image shaping should pay attention to urban culture, which is the important source of power, from the long run perspective.

2) The historical origin and regional characteristics of urban culture make city image form characteristics in the shaping process. The characteristic of city image is a sharp weapon for city to get involved in the competition. The image of city is the externalization of its characteristic and the visual presentation of the historical origin of the city. The shaping of city image should be established in specific culture and make the image of the city unique. Distinctive city image can leave deep impressions on the mind of people who are in touch with this city initially. Distinctive city will have more advantages in aspects such as attract investment, introduce talents and develop the tourism, etc.

3) Urban culture is an important part of city image and also the construction and inheritance of city spirit. Cultural image of the city is external representation of urban culture as well as important part of city image. The urban management idea, standard of behavior and goal of development in the design of city image all belong to the category of urban culture. The principal part of city image shaping is human and human is the creator of urban culture. The process of shaping city image is also the process of shaping human being. In the process of shaping human, it helps to enrich urban culture and form the image of urban culture.

4) Cultural strategy ideas and countermeasures and suggestions of city image shaping of Yantai. In the present world, it has become the trend of history to compete on culture. For Yantai, it must take the construction of ChinaSouth Korea Free Trade Area as the opportunity to research mixed cultural characteristics between China and South Korea and establish the strategic thinking of "cultural-based city". The shaping of city image should focus on urban culture of Yantai, deepen the reform of cultural system and make good long-term planning and improve the propaganda of city image through organizing various cultural activities.

Set up the idea of culture-oriented city image shaping. Fully excavate history and culture of the city. Under the background of China-South Korea Free Trade Area construction, actively absorb foreign excellent cultural achievements. Culture plays a guiding role in the shaping of city image. Setting up the idea of culture-oriented city image shaping is one of the shortcuts to establish individual character of urban culture and raise the image of city. Yantai pays attention to highlighting the unique port opening culture, ocean culture and red culture and build national-level famous historic and cultural city. Based on highlighting traditional culture of the city, it continuously absorbs the quintessence of foreign culture, especially the combination of culture in China and South Korea. Innovate continuously in the heritance to shape the city image of Yantai.

Deepen the reform of cultural management system and running mechanism, and take it as the breakthrough, inject vigor into the shaping of city image, give full play to the function of government leading and market regulation, constantly deepen the reform of cultural system, vigorously prosper cultural undertaking, speed up the development of cultural industry and improve the comprehensive strength of urban culture in Yantai. Only by promoting the prosperous development of urban culture can it inject a steady stream of vitality into the shaping of city image and then promote the development of the city.

Focus on long-term strategic planning and promote the development of urban culture and city image shaping. The city image shaping in Yantai cannot accomplish in an action. According to the requirements, formulate Development Planning of Urban Culture in Yantai, make city image reflect the uniqueness and supporting role of culture. The city image shaping in Yantai should integrate the resource of urban culture development and refer to the method of recognition system of corporate image and design recognition system of city concept, behavior identity system and visual identification system of the city. The design of identification system of city image should base on the unique culture in Yantai, put forward the urban management idea acknowledged and accepted by general public and formulate corresponding code of conduct to constraint daily behaviors of citizens.

Take various cultural activities as the carrier to enhance the propaganda of Yantai and enhance the popularity and reputation of Yantai; take various forms and different scales of cultural activities as the carrier to vigorously develop cultural undertakings and cultural industries. Creating a good environment for the development of culture is an effective way to intensify the propaganda of Yantai and improve the 
popularity and reputation of Yantai. In 2013, the propaganda film of city image of Yantai city appears on the "Chinese Screen" in Times Square. The city promotional film of Yantai use "fairyland on earth, the picturesque Yantai" as the subject, present the good image of Yantai to the entire world, attract the attention of domestic and overseas media and show the brand-new image of Yantai to the public at home and abroad.

\section{SHORTCOMINGS OF CITY IMAGE CONSTRUCTION OF YANTAI}

\section{A. Urban Planning Cannot Show the Image of Urban Landscape Very Well}

The most intuitive elements to evaluate urban planning are the environment quality and landscape after construction of the city is completed. As a material planning instrument of city image shaping, the attention that urban planning pays to image shaping is insufficient. It mainly shows in the following respects: firstly, problems exist in building the overall harmony of the city, which mainly show on the differences of city architectural style. When reconstruct and newly construct the surrounding buildings, it is necessary to pay attention to the mutual coordination between buildings and between buildings and the environment and ensure the surrounding architectural style conforms to its. Secondly, it lacks characteristics of streetscape. All the streets are all in the same key and let alone any characteristic. Thirdly, the characteristic of city layout is not obvious, so is the functional partition. Commercial area and dwelling district are in the same area. Residents in the city cannot have a good living environment. Fourthly, as windows and portals of the city, the railway station and bus station do not exploit their advantages to the full in the propaganda of city image.

\section{B. There are Many Shortcomings in City Square Construction of Yantai City}

City square is one of the most important urban public activity spaces and also can best embody the external environmental entities and inner quality of a city. Besides, square plays a very important role in the shaping of city space and environment. At present, with ever-increasing urban population of Yantai, the civil square in Yantai city is inadequate, which cannot meet the requirements of urban development.

\section{Problems Exist in the Construction of Urban Traffic}

The urban road traffic is comparable to the blood circulation of people. The running condition of road traffic situation directly affects the whole operation of organic entity in the city. In recent years, under the efforts of the government, the road traffic in Yantai city has been improved greatly. Most road conditions also have improvements, but several roads also have the phenomenon of pavement irregularity and traffic jam.

\section{Quality of the Residents Needs Improving}

Mainly reflect in: the management of migrant workers lacks standard and illegal events happen from time to time; in the process of urbanization, more and more land-lost farmers appear. They have lower educational degree and insufficient willingness to work and it is hard for them to find a job; citizens have not developed the idea of loving and protecting the environment; the educational level of citizens is not high and their competitive consciousness is not strong.

\section{E. The Urban Marketing Force is Insufficient.}

Urban marketing takes the city as a product and promotes it to customer groups such as investors and tourists to meet the requirements of the city and customers in the city. The marketing contents mainly have city image, attractive facilities in the city, city development principle and city government, etc. Yantai city has takes many measures in city marketing and it has received certain effects. But it also has the shortcomings such as the consciousness is not strong, the measures are limited and it lacks innovation.

\section{COUNTERMEASURES OF City IMAGE SHAPING OF YANTAI CITY}

\section{A. Further Improve the Urban Planning; Always Adhere to the Principle of Value Orientation of Putting the Interests of the Citizens above Everything Else.}

The principal parts of city development are the masses and the vast citizens. The city image shaping, city planning and city designing of Yantai should give full consideration to the interests of the citizens, the involvement of the public and pay attention to the role of public power in decision making.

\section{B. City Image Shaping Should Build Urban Characteristics and Continuously Enhance the Attraction and Appeal of the City}

The goal of city image shaping is to push city to the market and attract more external resources to promote urban economic development and attract and expand urban financial resources. Urban characteristics represent the personality characteristics of the city, is the essential attributes to distinguish cities, the symbol of vitality of the city, the foundation to build a city as well as the source of development. City image shaping must base on urban characteristics. Only by observing urban characteristics can the city image shaping show respect for "natural design". Only natural and agreeable city environment established on the basis of ecological environment balance can reflect the inheritance of regional culture and maintain the continuity and indigenization of urban context.

\section{City Image Shaping Should Pay Attention to the Molding of Urban Spirit.}

Urban spirit is the "soul" of a city, which has guide function, cohesive function and incentive function in city development. The establishment of urban spirit means citizens will use the common urban future orientation to 
promote the revitalization of urban civilization and it is the value premise of the whole city construction. At present, there is no elaboration and planning of urban spirit, which should be valued.

\section{Pay Attention to Construction of Urban Culture in City} Image Shaping

Urban culture is the core to shape city image and it gives good quality to city image. City image converge unique social and cultural environments in the city and it is cultural connotation that has distinctive characteristics. Yantai has advantaged natural resources and unique cultural resources. It should be a great topic about how to further develop and publicize cultural resources of Yantai city.

\section{E. Devote Greater Efforts to Publicity and Improve Popularity of the City}

Shape city image and publicize the city through media; show new image of Yantai city. Under the background of China-South Korea Free Trade Area construction, integrate quintessence of the culture in China and South Korea, expand the popularity of Yantai through vigorously developing the trade between China and South Korea, tourist industry and all kinds of cultural exchange activities; in addition, excavate folk custom, increase the development of folk craft and spread distinctive cooking culture to enhance the popularity of Yantai city.

\section{F. Positively Carry Out the Research on City Image}

Establish special organization, such as Urban Art Committee in Yantai City, to organize thematic activities to design and research city image of Yantai. Positively cultivate talents to research city image. Architectural colleges and colleges of art and design can open specialized courses of city image. Urban planning and construction industry can often invite specialists at home and abroad who are engaged in the research on city image to improve the level of city builders to shape city image.

\section{REFERENCES}

[1] Zhao Huo, Yu Dapeng. Shaping of Square and City Image [J]. China Science and Technology Information 2011 (10)

[2] Li Guangbin, Wang Yong, Yuan Zhongin. City Characteristics and City Image Shaping [J]. City Planning, 2010 (8)

[3] An Yunhua, Xu Wenhua. Analysis on Urban Culture and City Image Shaping [J]. Chinese and Overseas Architecture, 2012 (1)

[4] Chen Lixu. Urban Culture and Urban Spirit[M]. Nanjing: Southeast University Press, 2002

[5] An Yunhua, Xu Wenhua. Analysis on Urban Culture and City Image Shaping [J]. Chinese and Overseas Architecture, 2010 (5)

[6] Zhang Hongyan. Discussion on City Image and Urban Cultural Capital [M]. Nanjing: Southeast University Press, 2002

[7] Bao Zonghao. Discussion on the Spirit of Urban Culture [J]. Academic Monthly, 2010 (1)

[8] Wu Shengjia. Research on "Cultural Yantai" Development Road and Regional Culture [J]. Yangtze Tribune, 2012 (3) 